\title{
Article
}

\section{Torque-angle-velocity relationships and muscle performance of professional and youth soccer players}

Mazuquin, B.F, Bela, L.F.D, Pelegrinelli, A.R.M, Dias, J.M, Carregaro, R.L, Selfe, James, Richards, Jim, Brown, L.E, Moura, F and Cardoso, J.R

Available at http://clok.uclan.ac.uk/14574/

Mazuquin, B.F, Bela, L.F.D, Pelegrinelli, A.R.M, Dias, J.M, Carregaro, R.L, Selfe, James, Richards, Jim ORCID: 0000-0002-4004-3115, Brown, L.E, Moura, F et al (2016) Torque-angle-velocity relationships and muscle performance of professional and youth soccer players. International Journal of Sports Medicine, 37 (12). pp. 992-996. ISSN 0172-4622

It is advisable to refer to the publisher's version if you intend to cite from the work. http://dx.doi.org/10.1055/s-0042-108199

For more information about UCLan's research in this area go to

http://www.uclan.ac.uk/researchgroups/ and search for <name of research Group>.

For information about Research generally at UCLan please go to http://www.uclan.ac.uk/research/

All outputs in CLoK are protected by Intellectual Property Rights law, including Copyright law. Copyright, IPR and Moral Rights for the works on this site are retained by the individual authors and/or other copyright owners. Terms and conditions for use of this material are defined in the policies page. 
1 MAZUQUIN, B.F.; BELA, L.F.D.; PELEGRINELLI, A.R.M.; DIAS, J.M.; CARREGARO,

2 R.L.; SELFE, J.; RICHARDS, J.; BROWN, L.E.; MOURA, F. A.; CARDOSO,

3 J.R. Torque-angle-velocity relationships and muscle performance of professional and

4 youth soccer players. International Journal of Sports Medicine, 2016.

5

6 Abstract

7

8 Soccer matches consist of a variety of different activities, including repeated sprints.

9 Time to attain velocity (TTAV), load range (LR) and the torque-angle-velocity

10 relationship $\left(\mathrm{TAV}_{3 \mathrm{D}}\right)$ represent an important measurement of muscle performance

11 however there are few studies related. The aim of this study was to compare these outcomes between soccer players of different age category. Seventeen professional (PRO) and seventeen under-17 (U17) soccer players were assessed for concentric knee flexion/extension at 60, 120 and $300 \%$ s. For the extensor muscles, differences were found in favor of the U17 group for TTAV and LR outcomes at $120 \%$, however, the PRO group maintained higher torques in both movement directions in comparison to the $\mathrm{U} 17$ in $\mathrm{TAV}_{3 \mathrm{D}}$ evaluation. These results suggest that muscle performance of the PRO group is more efficient than the U17 group.

\section{INTRODUCTION}

Soccer matches consist of a variety of different physical demands and activities, including running which comprises repetitive periods of sprinting and walking $[2,10]$. Peak torque is the most commonly reported outcome measure when using an isokinetic device to assess strength of the lower limbs $[1,17,22]$. Time to attain 
velocity (TTAV) (the time to reach a target velocity) as well as load range (LR) (the capacity to maintain a given velocity during an isokinetic test) have been considered an important measurement of muscle performance and could help to discriminate player status following training intervention strategies $[4,7,8,30]$.

Another feature of muscle performance, which cannot be observed when single values of peak torque, average power or total work are reported, is the joint torqueangle-velocity relationship $\left(T A V_{3 D}\right)$. The $T A V_{3 D}$ represents the dynamic behavior of a muscle and can be applied to training [22] as a complement to the length-tension and length-velocity relationships, providing a more comprehensive assessment of functional capacity $[19,23]$.

During a soccer match, elite soccer players perform 150-250 brief intense actions, half of them are shorter than $10 \mathrm{~m}$ and almost all actions are shorter than $30 \mathrm{~m}$ [11]. This demonstrates the importance of the player being able to develop strength in the speed required to achieve the goal of the motor task. It is known that dominant limb and age can influence these outcomes [21], mainly between young players due to teenage years promote changes in growth and development [9], where the most advanced present greater muscle strength [29].

There is no consensus about the relationship between the isokinetic outcomes and functional testing. Some studies showed that the flexors/extensors peak torque, evaluated at different speeds, are not good predictors for the performance of functional tests as one-leg-hop, triple-jump, vertical-jump, one-leg-rising, square-hop and repeated-sprint ability $[11,27,28]$. While Cabri et al. [6] found a strong correlation ( $r=.77)$ between the distance of the kick and peak torque of knee extensors and flexors. 
However, little is known about the behavior of TTAV, LR and TAV ${ }_{3 D}$ between soccer players of different age category $[15,21]$. Thus, TTAV and LR may provide additional information regarding the effects of training programs, helping coaches and athletic trainers assess specific goals according to the needs of each player [5]. Thus, the aim of this study was to evaluate, describe and compare TTAV, LR and $\mathrm{TAV}_{3 \mathrm{D}}$ between soccer players of different age category.

\section{MATERIALS \& METHODS}

A total of 34 soccer players, who were preparing for regional and national competitions, volunteered to participate. The groups consisted of 17 professional players (PRO) of the First State League and seventeen under-17 (U17). The sample size was calculated through G*Power 3.1.9.2 [13] using a two-tailed Student $t$ test to find differences between groups, effect size estimated as 0.8, $\alpha=0.05$. Thirty-four subjects were necessary for a power of $82 \%$.

The inclusion criteria were: absence of lower limb injuries in the preceding three months, age over 20 years for the PRO group and age between 15 and 17 years for the U17. The athletes' characteristics are presented in TABLE 1. All testing occurred during the pre-season, one month before the season started. All participants read and signed an informed consent prior to the evaluation, this study meets the ethical standards of the journal [16] and all procedures were approved by the Universidade Estadual de Londrina Ethics Committee (\#055/2012). 
Evaluation procedures

All testing was carried out by the same investigator, in the Laboratory using a Biodex System 4® Dynamometer (Biodex Medical System Inc., Shirley, NY). Contraction mode was concentric isokinetic, at 60,120 and $300 \%$, for knee flexion/extension. Athletes were instructed not to train on the day of testing or the afternoon of the day before. The testing protocol was characterized by one set of five repetitions at each velocity, in random order, with a rest period of 90 seconds between sets [31]. Prior to the isokinetic test, participants warmed-up on a stationary cycle for 10 minutes. They were then positioned on the seat of the dynamometer, and stabilized by belts around their trunk, pelvis and thigh. Hip flexion was set at $85^{\circ}$ and the dynamometer axis was aligned with their lateral femoral epicondyle. The ankle pad was positioned just above their medial malleolus [20]. All calibration procedures and gravity correction procedures followed the manufacturers' instruction manual [3]. Range of motion was set from $90^{\circ}$ of flexion to $0^{\circ}$ extension, avoiding knee hyperextension. They were instructed to perform with maximum effort during all repetitions while verbal encouragement and visual feedback were provided. For reliability purposes, a coefficient of variation less than $10 \%$, for each set, was considered acceptable [26].

Prior to data collection, familiarization was conducted at each speed with one set of 10 repetitions at $300 \%$ and $120 \%$ with 90 seconds rest. At $60 \%$, only one set of 5 repetitions was performed (because of the difficulty of the speed). 
Data Analyses

Isokinetic data processing was performed with specific Matlab® algorithms. TTAV and LR (in milliseconds) were calculated as mean values from all five repetitions at 60, 120 and $300 \%$ s. TTAV considered the initial phase of ROM, representing the time taken to achieve the isokinetic velocity phase. From this, LR was calculated as the duration of the isokinetic phase when the predetermined velocity was maintained till beginning deceleration [6]. Sampling frequency was $100 \mathrm{~Hz}$.

To create the $\mathrm{TAV}_{3 \mathrm{D}}$ surface maps, the surf mathematical function from Matlab® was used. All five repetitions of each velocity were interpolated according to time duration. The algorithm estimated the intrinsic geometry by considering torque (zaxis), joint angle (x-axis) and velocity (y-axis) in the same time frame. The $z$ axis defines the map height in relation to strength intensity while the $\mathrm{x}$ and $\mathrm{y}$ axes shape boundaries of the surface. The dark grey color (FIGURES 1 and 2) demonstrates higher torque while light grey is lower torque. The color intensity is proportional to each surface throughout the ROM.

\section{Statistical analyses}

The Shapiro-Wilk test was used to verify data distribution, then the Mann-Whitney test was applied for comparisons between groups and the Wilcoxon test for comparison between the dominant and non-dominant legs. Statistical significance was set at 5\% and all analyses were performed with SPSS version 22.0 (IBM SPSS ${ }^{R}$, Armonk, NY, USA). 


\section{RESULTS}

No statistically significant differences were found between the dominant and non-dominant legs in both groups. All statistical differences between the groups were observed at $120 \%$ s for extension. The U17 group took longer to perform the repetition when compared to the PRO group, U17 total time: 840 ms; PRO total time: $820 \mathrm{~ms} ; P=.03$. Still, the U17 group had lower TTAV $(P<.001)$ and greater LR $(P=.005)$. However, for other outcomes, such as peak torque and total work at 120 \%s (TABLE 1), the PRO group showed better results. That occurred despite the U17 group's ability to maintain the speed longer when compared to the PRO group. However, the latter generated more torque and work in less time. More details can be seen in TABLES 2 - 4.

There were no differences for any other outcome. FIGURES 3 and $\mathbf{4}$ depict the maintenance of speed throughout the entire ROM. However, there were no differences between groups.

For $\mathrm{TAV}_{3 \mathrm{D}}$ analysis, the PRO group leg extension exhibited a larger dark grey area, extended until approximately $250 \%$ s, compared to the U17 group, which only extended to approximately $200 \%$ s. Furthermore, at the end of the ROM (joint angle of $0^{\circ}$ ) the PRO group demonstrated greater values than the U17 group. The TAV surface maps for extension for both groups are shown in FIGURE 1.

The flexion maps demonstrated different curves than extension, maintaining areas of high torque for a longer ROM and without a prominent peak torque. The PRO group had higher torque areas and, once again, during the final stage (joint angle of $90^{\circ}$ ), presented even smaller areas of lower torque when compared to extension. The $\mathrm{TAV}_{3 \mathrm{D}}$ surface maps of knee flexion for both groups are shown in FIGURE 2. 


\section{DISCUSSION}

This study only observed a statistical difference for knee extension TTAV and LR (120 \%), with lower values for the U17 group. The behavior of each muscle group, as presented by the $\mathrm{TAV}_{3 \mathrm{D}}$ surface maps, demonstrated that the PRO athletes were able to maintain higher torques during the test.

Differences in strength capacity (of extensors and flexors muscles) reported by peak torque have previously been shown between these two age category groups $[18,25]$. However, the results of the present study demonstrate that despite strength differences and physical demands in a soccer match [14], athletes of different ages have a similar ability to develop acceleration and knee joint velocity, with the exception of knee extension at $120 \%$ s. These muscles have an important role and may be associated with jumping, changing direction while running and kicking as well as movements where success is partially related to velocity [12].

The results demonstrate that the $\mathrm{U} 17$ group is able to maintain a required velocity for longer durations (larger LR), and therefore, it was expected that this group had also a lower TTVA because these outcomes are inter-related [5, 8, 19]. Le Gall et al. [23] stated that the quadriceps femoris presents maximum development at the age of 21 years while thereafter, performance seems to remain stable. Contrary to this, the hamstrings achieve their maximum improvement at the age of 16 years [25]. Thus, the fact that the majority of subjects in the U17 group had already reached this age (16 years) may explain the results for the flexors, because there was any difference between groups. For the results found for the extensors, the TVA 3 s surface map provides valuable information and a more detailed biomechanical analysis, because, 
although the U17 group shows better results for TTAV and LR, the PRO group maintained higher torques in both movement directions in comparison to the U17. That is, the muscle performance of the PRO group is more efficient than the U17 group. This conclusion can only be taken when analyzing the TVA 3D surface maps, hence it allowed for a broader view of the isokinetic assessment $[17,19,23]$. This study has some limitations, such as the maturational status of athletes and skill levels. It is suggested that in future studies the athletes should be separated into groups according to both characteristics. In addition, it is known that isokinetic evaluations (which are the gold standard for muscle performance) are not always available in practice. Several studies have related isokinetic results with field tests $[11,27,28]$, though none correlated the outcomes in this study with such tests, so further studies with these objectives are needed. Furthermore, the recommended rest periods between strength training could not be done due to logistical issues of the team. This may have biased the results. Finally, data presented here is representative of just one soccer team so caution should be exercised when extrapolating to other populations.

\section{CONCLUSIONS}

For the extensor muscles, differences were found in favor of the U17 group for TTAV and LR outcomes at $120 \%$ s. However, the TAV 3 D evaluation demonstrated that the PRO group maintained higher torques in both muscles in comparison to the U17.This suggests that muscle performance of the PRO group is more efficient than the U17 group. 
- The evaluation of outcomes such as TTAV and LR can provide information on muscle efficiency of athletes and serve as a support for strength training prescriptions. - Surface maps improve understanding of muscle behavior and allow for a complementary analysis that can support strength training prescriptions.

206

\section{REFERENCES}

1 Anderson DE, Madigan ML, Nussbaum MA. Maximum voluntary joint torque as a function of joint angle and angular velocity: Model development and application to the lower limb. J Biomech 2007; 40: 3105-3113

2 Bangsbo J. The physiology of soccer: With special reference to intense physical exercise. Acta Physiol Scand Suppl 1994; 619: 1-155

3 Biodex Medical System. Biodex multi-joint system. Isokinetic source book.

4 Brown LE, Whitehurst M, Findley BW. Reliability of rate of velocity development and phase measures of an isokinetic device. J Strength Cond Res 2005; 19: 189-192 device. J Orthop Sports Phys Ther 1995; 21: 107-112

2216 Cabri J, De Proft E, Dufour W, Clarys JP. The relation between muscular sthength and kick performance. $1^{\text {st }}$ ed. London, UK: E \& FN Spon; 1988

2237 Carvalho $P$, Cabri $P$. Isokinetic evaluation of the thigh muscles in soccer players. Rev Port Fisioter Desp 2007; 1: 4-13 
2258 Chollet-Tourny C, Léger H, Beuret-Blanquart F. Isokinetic knee muscles strength 226 of soccer players according to their position. Isokinet Exerc Sci 2000; 8: 187-193

2279 Chulani VL, Gordon LP. Adolescent growth and development. Prim Care 2014; 41: 465-487

10 Cormie $P$, McGuigan MR, Newton RU. Developing maximal neuromuscular power. Part 2 - training considerations for improving maximal power production. Sports Med 2011; 41: 125-146

11 CotteT, Chatard JC. Isokinetic strength and sprint times in English premier league football players. Biol. Sport 2011; 28:89-94

12 Cunha R, Carregaro R L, Martorelli A, Vieira A, Oliveira AB, Bottaro M. Effects of short-term isokinetic training with reciprocal knee extensors agonist and antagonist muscle actions: A controlled and randomized trial. Braz J Phys Ther 2013; 17: 137-145

13 Faul F, Erdfelder E, Lang AG, Buchner AG. G*Power 3: a flexible statistical power analysis program for the social, behavioral, and biomedical sciences. Behav Res Methods 2007; 39: 175-191

14 Frey-Law LA, Laake A, Avin KG, Heitsman J, Marler T, Abdel-Malek K. Knee and elbow 3D strength surfaces: Peak torque-angle-velocity relationships. J Appl Biomech 2012; 28: 726-737

15 Frisch A, Urhausen A, Seil R, Croisier JL, Windal T, Theisen D. Association between preseason functional tests and injury in youth football: a prospective follow-up. Scand J Med Sci Sports 2011; 21: e468-e476

16 Harriss DJ, Atkinson G. Ethical standards in sports and exercise science research: 2014 update. Int J Sports Med 2013; 34: 1025-1028 
17 Herdy C, Alkimim R, Selfe J, Pedrinelli A. Isokinetic testing of athletes Brazilian U17, U20 and professional [abstract]. 22 ${ }^{\text {nd }}$ International Conference on Sports Rehabilitation and Traumatology: Football Medicine Strategies for muscle and tendon injuries. London, UK:2013

18 Hill AV. The heat of shortening and the dynamic constants of muscle. Proc R Soc Biol 1938; 126: 612-745

19 Houwelling TAW, Hamzeh MA. Does knee joint alignment with the axis of the isokinetic dynamometer affect peak torque? Isokinet Exerc Sci 2010; 18: 217-221

20 Katis A, Giannadakis E, Kannas T, Amiridis I, Kellis E, Lees A. Mechanisms that influence accuracy of soccer kick. J Electromyogr Kinesiol 2013; 23: 125-131

21 Kellis E, Galanis N, Kapetanos G, Natsis K. Architectural differences between the hamstring muscles. J Electromyogr Kinesiol 2012; 22: 520-526

22 Khalaf KA, Parnianpour $M$, Karakostas $T$. Surface responses of maximum isokinetic ankle torque generation capability. J Appl Biomech 2000; 16: 52-59

23 Le Gall FL, Laurent T, Rochcongar P. Évolution de la force musculaire des fléchisseurs et extenseurs du genou mesurée par dynamomètre isocinétique concentrique chez le footballeur de haut niveau. Sci Sport 1999; 14: 167-172.

24 Lehance C, Binet J, Bury T, Croisier JL. Muscular strength, functional performances and injury risk in professional and junior elite soccer players. Scand J Med Sci Sports 2009; 19: 243-251

25 Lin PC, Robinson ME, Junior JC, O`Connor P. Detections of submaximal effort in isometric and isokinetic knee extension tests. J Orthop Sports Phys Ther 1996; 24: $19-24$ 
27226 Malina RM, Cumming SP, Kontos AP, Eisenmann JC, Ribeiro B, Aroso J.

273 Maturity-associated variation in sport -specific skills of youth soccer players aged

274 13-15 years. J Sports Sci 2005; $23: 515-522$

27527 Newman MA, Tarpenninc K, Marino FE. Relationships between isokinetic knee

276 strength, single-sprint performance, and repeated-sprint ability in football players.

277 J Strength Cond Res 2004; 18: 867-872

28 Ostenberg A, Roos E, Ekdahl C, Roos H. Isokinetic knee extensor strength and functional performance in healthy female soccer players. Scand J Med Sci Sports 1998; 8: 257-264

29 Payne VG, Isaacs LD. Human motor development. A lifespan approach. $3^{\text {rd }}$ ed. Mountain View, California: Mayfield Publishing Company; 1995

30 Reilly $T$, Williams AM, Nevill A, Franks A. A multidisciplinary approach to talent identification in soccer. J Sports Sci 2000; 18: 695-702

31 Schwartz FP, Bottaro M, Celes RC, Brown LE, Nascimento FAO. The influence of velocity overshoot movement artefact on isokinetic knee extension tests. J Sports Sci Med 2010; 9: 140-146 